\section{Speed and ease of tracheal intubation: priming with mivacurium compared with succinylcholine}

Lester Molbegott MD, Thomas Baker MS
This study examined the efficacy of mivacurium priming $(0.015$ $\mathrm{mg} \cdot \mathrm{kg}^{-1}$ ) with five minutes between the priming and intubating doses by comparing the effects of one, two and three times the $E D_{95}$ dose $\left(0.075 \mathrm{mg} \cdot \mathrm{kg}^{-1}\right)$ of mivacurium after priming (Groups 1, 2 and 3, respectively), with a saline prime and $2 \times E D_{95}$ mivacurium (Group 4) or $1 \mathrm{mg} \cdot \mathrm{kg}^{-1}$ dase of succinylcholine (Group 5). The time from the intubating dase injection to intubation was measured and intubating conditions were rated on a five-point scale with 4 being optimal and 0 being failure. Mean times ( $\pm S E M$ ) in seconds between the administration of the intubating dose and tracheal intubation were: $106.4 \pm 5.1,89.6 \pm 6.7,81.9 \pm 2.7,169.9 \pm 7.8$ and $82.9 \pm 3.5$ for Groups $1-5$ respectively. The times for Group $2\left(2 \times E D_{95}\right.$ with priming), Group 3 ( $3 \times E D_{95}$ with priming) and Group 5 (succinylcholine with saline) were shorter than the times of Groups $1\left(1 \times E D_{95}\right.$ with priming) and $4(2 \times$ $E D_{95}$ with saline) $P<0.05$. Mean intubating condition scores $( \pm S D)$ for the five groups respectively were $3.1 \pm 0.6,3.4 \pm$ $0.6,3.5 \pm 0.5,3.2 \pm 0.6$ and 3.8 \pm 0.4 . Scores for Groups 2, 3 and 5 were higher than those of Group $1(P<0.05)$. The data demonstrated that (1) priming with mivacurium shortens the intubation time and is accompanied by good intubating conditions with doses $2 \times$ and $3 \times E D_{95}$, and (2) intubating times and conditions similar to those achieved with succinylcholine can be obtained using mivacurium $2 \times$ (total dose $0.150 \mathrm{mg} \cdot \mathrm{kg}^{-1}$ ) or $3 \times E D_{95}$ (total dose $0.215 \mathrm{mg} \cdot \mathrm{kg}^{-1}$ ) with a five-minute priming interval. Priming provides an al-

\section{Key words}

INTUBATION, TRACHEA: technique;

NEUROMUSCULAR RELAXANTS: mivacurium, succinylcholine, priming.

From the Department of Anesthesiology, Monmouth Medical Center, Long Branch, NJ 07740.

Address correspondence to: Dr. Lester Molbegott,

Department of Anesthesiology, Monmouth Medical Center,

300 Second Avenue, Long Branch, NJ 07740, USA.

Accepted for publication 13th May, 1995. ternative technique in those clinical circumstances where succinylcholine is contraindicated.

Cette étude porte sur l'éfficacité de la dose de précurarisation de mivacurium $\left(0,015 \mathrm{mg} \cdot \mathrm{kg}^{-1}\right)$ administrée cinq minutes avant la dose dintubation. Les effets de une, deux et trois fois l'ED $95\left(0,075 \mathrm{mg} \cdot \mathrm{kg}^{-1}\right)$ de mivacurium, administré après la précurarisation (respectivement les groupes 1, 2 et 3), sont comparés à la "précurarisation" au soluté physiologique et 2 fois l'ED $D_{95}$ de mivacurium (groupe 4) ou à $1 \mathrm{mg} \cdot \mathrm{kg}^{-1}$ de succinylcholine (groupe 5). Lintervalle entre la dose dintubation et lintubation est mesuré et les conditions d'intubation sont graduées sur une échelle de cinq point où 4 représente l'optimum et 0 l'échec. L'intervalle moyen ( \pm SEM) in secondes entre l'administration de la dase dintubation et lintubation sont: $106,4 \pm 5,1,89,6 \pm 6,7,81,9 \pm 2,7,169,9 \pm 7,8$ et 82,9 $\pm 3,5$ pour les groupes de 1 à 5 respectivement. Les intervalles pour le groupe 2 ( $\times E D_{9 s}$ avec précurarisation), le groupe $3\left(3 \times E D_{95}\right.$ avec précurarisation) et le groupe 5 (succinylcholine avec physiologique) sont plus courts que les intervalles pour les groupes $1\left(1 \times E D_{95}\right.$ avec précurarisation) et $4\left(2 \times E D_{95}\right.$ avec physiologique), $P<0.05$. Les scores dintubation moyens ( $\pm S D$ ) pour les cinq groupes sont respectivement de 3,1 $\pm 0,6$, 3,4 $\pm 0,6,3,5 \pm 0,5,3,2 \pm 0,6$ et de 3,8 $\pm 0,4$. Les scores des groupes 2, 3 et 5 sont plus élevés que ceux du groupe $1(P<0.05)$. Ces données montrent que 1) la précurarisation au mivacurium abrège lintervalle de lintubation et s'accompagne de bonnes connditions dintubation avec des doses de $2 \times$ et $3 \times E D_{95}$, et 2) la rapidité dintubation et les conditions d'intubation identiques à celles de la succinylcholine peuvent être obtenues avec du mivacurium $2 \times E D_{95}$ (dose totale 0.150 $\mathrm{mg} \cdot \mathrm{kg}^{-1}$ ) ou $3 \times E D_{95}$ (dose totale $0.215 \mathrm{mg} \cdot \mathrm{kg}^{-1}$ ) avec un intervalle de cinq minutes après la précurarisation. La précurarisation procure une solution de rechange intéressante dans les circonstances où la succinylcholine est contre-indiquée.

Mivacurium is a recently introduced short-acting nondepolarizing muscle relaxant. With the increasing number of same day surgical procedures, methods of using 
short-acting muscle relaxants to produce rapid onset times accompanied by optimal intubating conditions are important. Such methods would provide an alternative to succinylcholine in those patients with an absolute or relative contraindication to its use. ${ }^{1}$ This study determined the tracheal intubating conditions and times after several doses of mivacurium with priming and compared them with those produced by mivacurium without priming, and by succinylcholine.

The priming dose of mivacurium was $0.015 \mathrm{mg} \cdot \mathrm{kg}^{-1}$ which was determined by a preliminary study in which patients were given $1 / 10$ of an intubating dose (0.15 $\mathrm{mg} \cdot \mathrm{kg}^{-1}$ ) five minutes before the induction of anaesthesia. ${ }^{2}$ Intubation was not set at predetermined time periods after the administration of the intubating dose. Rather it was based upon clinical observations such as jaw relaxation and changes in respirıtory compliance, which duplicate clinical practice.

\section{Methods}

The study protocol was approved by the Institutional Research Review Board and informed consent was obtained from all patients. Any patient with a neuromuscular or metabolic disease, a history of a difficult intubation, or who was taking medication affecting neuromuscular function was excluded from the study.

No premedication was administered. Anaesthesia was induced with thiopentone $4-5 \mathrm{mg} \cdot \mathrm{kg}^{-1} i v$, fentanyl 1.5 $\mu \mathrm{g} \cdot \mathrm{kg}^{-1} \dot{i} v$ and midazolam $30 \mu \mathrm{g} \cdot \mathrm{kg}^{-1} \dot{i}$, and was maintained with a balanced technique using nitrous oxide and fentanyl. The patients were placed on a ventilator following intubation of the trachea. Blood pressure (once every $3 \mathrm{~min}$ ), ECG, $\mathrm{SpO}_{2}$, temperature and both inspired and expired gases were continuously monitored.

Patients were randomly divided into five groups of 14 persons: groups 1-3 were primed with mivacurium while groups 4-5 were given a saline placebo injection (Table I). The priming dose of mivacurium was $0.015 \mathrm{mg} \cdot \mathrm{kg}^{-1}$ and a five minute waiting period was observed between the injections of the priming or placebo and the intubating doses.

All intubating doses of mivacurium were injected over 30 sec. Groups 1-3 were administered intubating doses of mivacurium such that with the priming dose, the total doses were $1 \times \mathrm{ED}_{95}, 2 \times \mathrm{ED}_{95}$ and $3 \times \mathrm{ED}_{95},{ }^{3}$ respectively (Table I). Groups 4 and 5 were primed with saline; Group 4 received an intubating dose that was 2 $\times \mathrm{ED}_{95}$ and Group 5 was administered succinylcholine, $1 \mathrm{mg} \cdot \mathrm{kg}^{-1}\left(3 \times \mathrm{ED}_{95}\right){ }^{4}$

The ulnar nerve was supramaximally stimulated at the wrist using surface electrodes. Stimulation consisted of trains-of-four rectangular pulses of $0.2 \mathrm{msec}$ duration at a frequency of $2 \mathrm{~Hz}$ delivered once every $12 \mathrm{sec}$. In a few patients, the muscle responses were monitored visually; with most, the responses of the adductor muscle were monitored with a force transducer (Professional Instrument Adductor Pollicis Monitor, Houston, TX). In addition, non-invasive blood pressure, heart rate, pulse oximetry and temperature of every patient were monitored and recorded throughout the operative period.

The same anaesthetist (with ten years of clinical experience) performed all the intubations. He could not observe the train-of-four responses of the adductor pollicis muscle and was not told which drug or dose was given to the patient. The time from the end of the intubating injection dose to the end of intubation of the trachea was measured and was defined as the intubating time.

The status of intubating conditions and clinical relaxation were rated on a scale of 0-4 (Table II): 4 being optimal, with the jaw well relaxed, the cords fully abducted and the intubating conditions excellent; 3 being good, with the jaw not completely relaxed, the cords partially abducted but immobile, and without associated muscular response affecting or consequent to endotracheal intubation; 2 being fair, with the jaw poorly relaxed, the cords minimally abducted, and the intubation effort associated with diaphragmatic contraction and/or slight coughing; 1 being difficult, with no relaxation of the jaw nor abduction of the vocal cords, and with concomitant contractions of the diaphragm and trunk muscles, and/or vigorous coughing; 0 being failure, resulting from the inability to intubate due to poor relaxation. ${ }^{5}$

Patients' faces and chests were observed for any flushing which occurred after the administration of the intubating doses of mivacurium. Systolic and diastolic blood pressures were recorded upon arrival in the operating room and following the priming and intubating injections.

Power analysis was used to determine the sample size for showing differences in intubation times. It was estimated for the preliminary study that the intubation times of $15 \%$ of the primed patients would fall within the range of values for the non-primed control mivacurium intubation times. With a power value of 0.95 , the sample size had to be at least 13; the sample size for the study was set at 14 (overlap occurred in only one group, 1 $\times \mathrm{ED}_{95}$ and it was $7.1 \%$ ). All data were analyzed using the analysis of variance and the Newman-Keuls comparison tests except the incidences of flushing which were analyzed using the Fisher exact test and the intubating scores which were analyzed using the Kruskal-Wallis non-parametric rank and the Newman-Keuls comparison tests. The Kruskal-Wallis. test compares the rank order of data for three or more independent groups. The Newman-Keuls procedure makes pair comparisons of three or more groups and can compare the means (for 
TABLE I Dose regimen

\begin{tabular}{llllll}
\hline Group & $\begin{array}{l}\text { Priming } \\
\text { period } \\
\text { min }\end{array}$ & $\begin{array}{l}\text { Priming } \\
\text { drug } \\
m g \cdot k g^{-1}\end{array}$ & $\begin{array}{l}\text { Intubating } \\
\text { drug } \\
m g \cdot \mathrm{kg}^{-1}\end{array}$ & $\begin{array}{l}\text { Total } \\
\text { dase } \\
\mathrm{mg} \cdot \mathrm{kg}^{-1}\end{array}$ & $\begin{array}{l}E D_{95} \\
\text { equivalent }\end{array}$ \\
\hline 1 & 5 & Miv 0.015 & Miv 0.060 & 0.075 & 1 \\
2 & 5 & Miv 0.015 & Miv 0.135 & 0.15 & 2 \\
3 & 5 & Miv 0.015 & Miv 0.200 & 0.215 & 3 \\
4 & 5 & Saline & Miv 0.150 & 0.15 & 2 \\
5 & 3 & Saline & Sux 1 & 1 & 3 \\
\hline
\end{tabular}

TABLE II Rating of intubation conditions

\begin{tabular}{|c|c|c|}
\hline Score & Rating & Conditions \\
\hline 4 & Optimal & Jaw fully relaxed, cords fully abducted, no movement. \\
\hline 3 & Good & Jaw not fully relaxed, cords partially abducted, slight movement. \\
\hline 2 & Fair & $\begin{array}{l}\text { Jaw poorly relaxed, cords poorly abducted, associated diaphragmatic conditions } \\
\text { some coughing. }\end{array}$ \\
\hline 1 & Difficult & $\begin{array}{l}\text { Jaw not relaxed, cords not abducted, concomitant diaphragmatic and trunk } \\
\text { muscle contractions, vigorous coughing. }\end{array}$ \\
\hline 0 & Failure & Unable to intubate due to poor relaxation. \\
\hline
\end{tabular}

normally distributed data) or mean ranks (for data not normally distributed). Significance was at $P<0.05$. The statistical data analysis programme employed was Kwikstat ${ }^{\circledR}$ by TexaSoft.

\section{Results}

Patients' ages ranged from 19 to $74 \mathrm{yr}$ with a mean of $38.6 \pm 13.6( \pm \mathrm{SD})$. The range in weight was from 40.7 to $100.0 \mathrm{~kg}$ with a mean $( \pm \mathrm{SD})$ of $69.9 \pm 15.2 \mathrm{~kg}$. Thirteen patients were female and 57 male. All patients were of ASA physical status 1 or 2, and were undergoing gynaecological, orthopaedic, general surgical, minor peripheral vascular or ear, nose and throat procedures.

There were no differences in the demographic characteristics among the five groups (Table III). The intubating doses of $2 \times \mathrm{ED}_{95}$ and $3 \times \mathrm{ED}_{95}$ completely depressed the train-of-four responses. Among the patients who received the $1 \times \mathrm{ED}_{95}$ dose of mivacurium, however, the train-of-four responses were not completely blocked in five patients.

The trachea of each patient was successfully intubated. The intubating times were distributed into three statistically different populations $(P<0.05)$. In the first, were Groups 2, 3, and 5, mivacurium with priming for $2 \times$ $\mathrm{Ed}_{95}$ and $3 \times \mathrm{Ed}_{95}$, and succinylcholine $3 \times \mathrm{ED}_{95}$ with mean times $( \pm \mathrm{SEM})$ of $89.6 \pm 1.5 \mathrm{sec}, 81.9 \pm 2.7 \mathrm{sec}$ and $82.9 \pm 3.52 \mathrm{sec}$, respectively. The second population included only Group 1 , mivacurium $1 \times \mathrm{ED}_{95}$ with priming, which had a mean time of $106.4 \pm 5.05 \mathrm{sec}$. The third population contained only Group 4, mivacurium
TABLE III Demographic characteristics (mean \pm SD)

\begin{tabular}{llll}
\hline Group & $\begin{array}{l}\text { Weight } \\
(\mathrm{kg})\end{array}$ & $\begin{array}{l}\text { Age } \\
(\mathrm{yr})\end{array}$ & $\begin{array}{l}\text { Sex } \\
(\mathrm{m} / \mathrm{f})\end{array}$ \\
\hline 1 & $74.2 \pm 11.6$ & $36.9 \pm 11.7$ & $3 / 11$ \\
2 & $70.0 \pm 15.8$ & $38.6 \pm 16.5$ & $3 / 11$ \\
3 & $61.6 \pm 14.3$ & $34.4 \pm 7.91$ & $2 / 11$ \\
4 & $71.4 \pm 17.4$ & $39.9 \pm 14.0$ & $2 / 11$ \\
5 & $72.3 \pm 15.2$ & $43.2 \pm 16.5$ & $3 / 11$ \\
\hline
\end{tabular}

$2 \times \mathrm{ED}_{95}$ without priming, which had a mean time of $169.9 \pm 7.8$ seconds.

Intubating conditions were rated from fair to optimal (intubating scores 2 to 4 ) in all groups (Table IV).

Of the 42 patients that were primed with mivacurium, none had double vision, droopy eyelids or tightness of the chest.

Systolic and diastolic blood pressures were not significantly different within each of the four groups of patients who were given mivacurium (Table IV).

Flushing occurred only in patients in Group 3, mivacurium $3 \times \mathrm{ED}_{95}$ with priming. Four of the 14 patients in this group experienced flushing. The incidence of flushing in this group was different from the other three groups.

\section{Discussion}

The mivacurium groups with priming which received 2 $\times \mathrm{ED}_{95}$ and $3 \times \mathrm{ED}_{95}$ doses, and the group which re- 
TABLE IV Summary of intubating conditions

\begin{tabular}{|c|c|c|c|c|c|c|}
\hline $\begin{array}{l}\text { Intubating } \\
\text { conditions }\end{array}$ & $\begin{array}{l}\text { Score } \\
\text { value }\end{array}$ & Group 1 & Group 2 & Group 3 & Group 4 & Group 5* \\
\hline \multicolumn{7}{|c|}{ A Number of intubations in each intubation condition } \\
\hline Optimal & Four & 3 & 7 & 7 & 4 & 12 \\
\hline Good & Three & 9 & 6 & 7 & 9 & 2 \\
\hline Fair & Two & 2 & 1 & 0 & 1 & 0 \\
\hline Difficult & One & 0 & 0 & 0 & 0 & 0 \\
\hline Failed & Zero & 0 & 0 & 0 & 0 & 0 \\
\hline \multicolumn{7}{|c|}{ B Group percentile } \\
\hline $25 \%$ & & 3 & 3 & 3 & 3 & 4 \\
\hline $50 \%$ & & 3 & 3.5 & 3.5 & 3 & 4 \\
\hline $75 \%$ & & 4 & 4 & 4 & 4 & 4 \\
\hline \multicolumn{7}{|c|}{$C$ Group mean scores $\pm S D$} \\
\hline & & $3.1 \pm 0.6$ & $3.4 \pm 0.6$ & $3.5 \pm 0.5$ & $3.2 \pm 0.6$ & $3.8 \pm 0.3$ \\
\hline
\end{tabular}

*Statistically different from Groups 1 and $4, P \leq 0.05$.

ceived succinylcholine had the shortest intubation times. The difference between the fastest and slowest mean times among these groups was less than eight seconds, with no statistical difference among them. The group administered $2 \times \mathrm{ED}_{95}$ mivacurium without priming had the longest intubation time $(P<0.05)$. The mean time was $170 \mathrm{sec}$ and was similar to onset times previously reported. ${ }^{6}$ The intubation time of the group which received mivacurium $1 \times \mathrm{ED}_{95}$ with priming was 106 seconds which was statistically different from the times of the four other groups. Even in this group, priming reduced the intubation time, although not as much as with the larger intubating doses.

The tracheas of all patients were successfully intubated. Among the five groups, Group $3,3 \times \mathrm{ED}_{95}$ with priming, and Group 5, succinylcholine, were the only groups which had all intubation scores in the 3 (good) and 4 (optimal) range (Table IV). Group 3 had seven optimal and seven good scores, and Group 5 had 12 optimal and two good scores. Analysis did not show any difference between the two groups. While a larger sample size may demonstrate a difference, the difference would not be clinically important, for intubating under good conditions presents little difficulty (Table II). The other groups in this study had some ratings in the fair range, but none were difficult nor were there any failures.

Group 3, mivacurium $3 \times \mathrm{ED}_{95}$ with priming, did have a higher incidence of flushing, but this group did not experience any changes in blood pressure (Table V).

From the time the priming principle was introduced into the practice of anaesthesia, ${ }^{7}$ much controversy has existed concerning the effectiveness of the priming dose in shortening the time between the administration of an intubating dose of a nondepolarizing muscle relaxant and
TABLE V Percent changes in systolic and diastolic blood pressure following mivacurium administration

\begin{tabular}{llllll}
\hline & \multicolumn{2}{l}{ Priming injection } & & \multicolumn{2}{c}{ Intubation injection ${ }^{2}$} \\
\cline { 2 - 3 } \cline { 5 - 6 } Group & $S P$ & $D P$ & & $S P$ & \multicolumn{1}{c}{$D P$} \\
\hline 1 & $-6.3 \%$ & $-6.4 \%$ & & $3.6 \%$ & $2.9 \%$ \\
2 & $-5.0 \%$ & $-4.0 \%$ & & $1.5 \%$ & $1.2 \%$ \\
3 & $-6.3 \%$ & $-3.4 \%$ & & $-0.8 \%$ & $-3.1 \%$ \\
4 & $-7.1 \%$ & $-6.3 \%$ & & $10.8 \%$ & $7.0 \%$ \\
\hline
\end{tabular}

*Compared with pressures taken upon arrival in operating room. †Compared with pressures taken following the priming dose.

intubation. $^{8-10}$ Jones believes that while priming does work, it presents the patients with unacceptable high incidences of potentially dangerous undesired side effects. ${ }^{10}$ Patients can experience some degree of paralysis when the priming doses are $>10 \%$ of the intubating dose. ${ }^{9,11}$ In the preliminary ${ }^{1}$ and present studies, however, patients who were primed with $0.015 \mathrm{mg} \cdot \mathrm{kg}^{-1}$ of mivacurium (1/10 of a $0.15 \mathrm{mg} \cdot \mathrm{kg}^{-1}$ intubating dose) did not experience any diplopia, ptosis, chest tightness or voiced any other complaint. In our studies with other nondepolarizing muscle relaxants, priming doses that were $1 / 10$ of the usual intubating doses did not produce any of these undesired dose-related effects. ${ }^{12-14}$ Using small priming doses avoids this potential hazard. If small priming doses are used, then the length of the interval between the priming and intubating doses becomes important. 15 Using various non-depolarizing muscle relaxants, Glass et al. demonstrated that the priming doses reached maximal effect $4.5-7 \mathrm{~min}$ after their administration. ${ }^{9}$ Thus, a five-minute priming period was selected to be used with mivacurium. The data from this study clearly shows 
that priming effectively reduces the intubation time, while intubating conditions remain good. Even the $1 \times \mathrm{ED}_{95}$ mivacurium dose with priming had a shortened intubation time as compared with mivacurium $2 \times \mathrm{ED}_{95}$ without priming and yet produced similar intubating conditions.

The neuromuscular blocking regimens which produced the fastest intubation times and the better intubating conditions were the mivacurium doses $2 \times \mathrm{ED}_{95}$ and $3 \times$ $\mathrm{ED}_{95}$ with priming, and succinylcholine. There were no differences among these three groups in terms of rapid intubation nor any major clinical differences in intubation conditions. Mostly good and optimal intubating conditions can be obtained utilizing the mivacurium dose 2 $\times \mathrm{ED}_{95}$ with priming and without any prolongation of neuromuscular block. While either mivacurium protocol can produce intubating times and conditions that are similar to those obtained with succinylcholine, using the 3 $\times \mathrm{ED}_{95}$ should assure obtaining good intubating conditions and rapid intubation.

The data from this study clearly demonstrate that a rapid onset of action can be achieved by using a priming dose of mivacurium of $0.015 \mathrm{mg} \cdot \mathrm{kg}^{-1}$ and waiting five minutes to administer an intubating dose $0.200 \mathrm{mg} \cdot \mathrm{kg}^{-1}$ $\left(3 \times \mathrm{ED}_{95}\right)$. In fact, using this technique resulted in intubating times and conditions that were clinically similar to those produced by succinylcholine. Thus, this protocol can be used and should be considered in those clinical situations where succinylcholine is contraindicated and cannot be utilized to facilitate tracheal intubation.

\section{References}

1 Gronert GA, Theye RA. Pathophysiology of hyperkalemia induced by succinylcholine. Anesthesiology 1975; 43: 89-99.

2 Molbegott L, Flashburg M, Patel N, Handlin DS, Baker T. Speed and ease of endotracheal intubation: priming with mivacurium compared with succinylcholine. Anesthesiology 1992; 77: A967.

3 Frampton JE, McTavish D. Mivacurium: a review of its pharmacology and therapeutic potential in general anaesthesia. Drugs 1993; 45: 1066-89.

4 Smith $C E$, Donati F, Bevan DR. Dose-response curves for succinylcholine: single versus cumulative techniques. Anesthesiology 1988; 69: 338-42.

5 Blitt CD, Carlson GL, Rolling GD, Hameroff SR, Otto $C W$. A comparative evaluation of pretreatment with nondepolarizing neuromuscular blockers prior to the administration of succinylcholine. Anesthesiology 1981; 55: 687-9.

6 Savarese JJ, Ali HH, Basta SJ, et al. The clinical neuromuscular pharmacology of mivacurium chloride (BW B1090U). Anesthesiology 1988; 68: 723-32.

7 Schwarz S, Ilias W, Lackner F, Mayrhofer O, Foldes FF.
Rapid tracheal intubation with vecuronium: the priming principle. Anesthesiology 1985; 62: 388-91.

8 Donati $D$. The priming saga: where do we stand now? (Editorial). Can J Anaesth 1988; 35: 1-4.

9 Glass PSA, Wilson W, Mace JA, Wagoner $R$. Is the priming principle both effective and safe? Anesth Analg 1989; 68: 127-34.

10 Jones $R M$. The priming principle: how does it work and should we be using it? (Editorial). Br J Anaesth 1989; 63: 1-3.

11 Harrop-Griffiths $A W$, Grounds $R M$, Moore $M$. Intubating conditions following pre-induction priming with alcuronium. Anaesthesiology 1986; 41: 282-6.

12 Handlin DS, Paskin S, Baker T. A study of the priming principle using pipecuronium. Anesth Analg 1992; 74: S129.

13 Karasic $L$, Handlin DS, Patel N, Baker $T$. Applying the priming principle to reduce atracurium intubating dose. Anesthesiology 1992; 77: A937.

14 Patel N, Handlin DS, Taylor M, Paskin S, Baker T. The priming principle reduces the intubating dose of vecuronium. Anesth Analg 1993; 76: S321.

15 Naguib $M$, Gyasi $H K$, Abdulatif $M, A b s o o d G H$. Rapid tracheal intubation with atracurium - a comparison of priming intervals. Can Anaesth Soc J 1986; 33: 150-6.

16 Savarese JJ, Ali HH, Basta SJ, et al. The candiovascular effects of mivacurium chloride (BW B1090U) in patients receiving nitrous oxide-opiate-barbiturate anesthesia. Anesthesiology 1989; 70: 386-94. 